\section{Analyzing the}

\section{Development and}

\section{Implementation}

\section{Posibility of the}

Robotic Ambulance for

COVID Pacients

\section{[Analiza posibilității realizării şi}

utilizării unei ambulanțe

robotizate pentru pacienții

COVID]

\section{Doru-Laurean BĂLDEAN ${ }^{1}$ Viorel CHINDEA ${ }^{2}$}

${ }^{1}$ Lecturer, Department of Automotive Engineering and Transportation at Technical University from Cluj-Napoca, Cluj-Napoca, Romania, dorubaldean@yahoo.com

${ }^{2}$ PhD Student, Department of Automotive Engineering and Transportation at Technical University from Cluj-Napoca, Cluj-Napoca, Romania, viorel chindea@yahoo.es
Abstract: During Covid pandemic, the automation, robotization and digitization were accelerated, but the results do not meet all expectations. Telecommunications have undeniable successes, but in other sectors the benefits of technological advancement are still missing. The "online school" and the "online procedures" of some institutions have been partially upgraded, but things have not been as well in other activities which were less suitable for automation, robotization and digitization. The healthcare sector was highly stressed in the context of COVID-19 crisis, but it has not fully benefited from the advantages of the robotic vehicles. Life and death during COVID-19 crisis has affected most people, either as victims or actors in a reality that took them unprepared. Ambulances have been challenged by events which were not always managed successfully. They must respond promptly to save the lives of those who call for help. Staff in this sector are often overworked and highly stressed. The simultaneous existence of robotic ambulances that can take over some of the victims who need medical services could be both a good idea and a life-saving measure. The paper proposes implementation of existing technology for optimizing ambulance services with robotic tools and suitable procedures for digitization. In this way, complementary solutions can be generated for increasing the quality of life, respectively for mitigating the emotional and physical stress when it comes to near death experiences. When onsite complex resuscitation and first aid maneuvers are not necessary, being required only the lifting and transportation procedures by a medical robot, the use of a robotic vehicle mitigates the ambulance's personnel from stresses. These solutions are complementary, leading to an improvement in life's quality.

Keywords: ambulance, automation, digitization, robotics, life

How to cite: Băldean, D.-L., \& Chindea, V. (2021). Analyzing the Development and Implementation Posibility of the Robotic Ambulance for COVID Pacients. Journal for Social Media Inquiry, 3(1), 8-18.

https://doi.org/10.18662/jsmi/3.1/13 


\section{Contextualizarea problemei studiate}

Pe durata pandemiei Covid schimbările au favorizat procesele de automatizare, robotizare şi digitalizare însă nivelul atins până la acest moment nu corespunde aşteptărilor. Domeniul telecomunicațiilor a înregistrat o serie de succese incontestabile, dar în alte sectoare socioprofesionale evoluția şi beneficiile avansului tehnologic se mai lasă încă aşteptate. Dacă prin „şcoala online” şi prin „procedurile online” ale unor administraţii s-au degrevat parțial anumite instituții, nu la fel de bine au mers lucrurile cu alte organisme ale căror activități nu sunt pretabile automatizării, robotizării şi/sau digitalizării la acest moment. Domeniul sanitar, chiar dacă este unul dintre sectoarele prioritare în contextul crizei COVID-19, încă nu beneficiază nici pe departe de avantajele nivelului la care se află tehnologia în acest moment. Viaţa şi moartea în contextul crizei COVID-19 a reuşit să-i sensibilizeze pe cei mai mulți, fie prin postura de victime, fie prin cea de actori într-un scenariu care i-a luat pe nepregătite pe majoritatea. Serviciile de ambulanță au fost şi sunt asaltate cu urgențe sanitare la care nu întotdeauna reuşesc să facă față cu succes şi să răspundă cu promptitudine astfel încât să salveze viaţa celor afectaţi. Personalul care deserveşte acest sector este adesea suprasolicitat şi supus unui stres nemeritat. Existența simultană a unor ambulanțe robotizate care să poată prelua o parte dintre victimele care au nevoie de servicii medicale şi asistenţă ar putea fi nu doar o idee bună ci chiar o măsură salvatoare. În studiul de faţă se propune analiza ideii de implementare a tehnologiei existente pentru optimizarea serviciilor de ambulanţă cu instrumente robotizate şi pretabile digitalizării. În felul acesta se pot oferii soluții şi idei complementare pentru creşterea calităţii şi expectanței vieții, respectiv pentru ameliorarea şi estomparea solicitărilor de ordin emoțional şi psiho-somatic când vine vorba despre iminenţa morţii. Pentru cazurile în care nu sunt necesare manevre complexe de resuscitare şi prim ajutor la fața locului în teren, fiind necesare doar transportul şi o serie de proceduri programabile şi executabile de un robot sanitar, ideea utilizării unei ambulanțe robotizate conduce la degrevarea personalului ambulanțier de o serie de solicitări. Măsurile şi soluțiile oferite au caracter complementar, conducând la îmbunătățirea calității vieții.

\section{Analiza referințelor de specialitate}

Analizând zona interfeței, pe durata interacțiunii om-tehnologie, în cazul echipajelor medicale de urgență, se poate observa că există oportunități de dezvoltare şi modelare a unor programe de control, a inteligenței 
artificiale şi a sectorului automotive în sensul convergenței spre realizarea şi implementarea vehiculelor automate sau robotizate care să deservească serviciile de urgență şi personalul medical din unităţile de profil (Andrei et al., 2020). Problema transportului pacienților şi interacțiunea om-om, respectiv cea dintre om-tehnologie, reprezintă încă o prioritate când se pune în discuție optimizarea sistemului medical de urgență. În cazul pandemiei Covid-19, unitățile medicale specializate pe boli infecțioase şi cele de primiri urgențe au fost deopotrivă supra-solicitate şi supuse unor sarcini şi rigori mai mari decât în anii precedenți. Anumite categorii de personal au fost suprasolicitate, în timp ce unor categorii de pacienți care probabil ar fi avut nevoie de transport şi de îngriijiri, acestea fie le-au fost refuzate, fie li s-au acordat cu o oarecare întârziere datorită numărului redus de vehicule pentru transportul pacienților care au solicitat ambulanța în comparație cu numărul foarte mare de apeluri.

La momentul curent se urmăresc şi se cercetează posibilitățile de estompare sau compensare a vulnerabilităţilor inerente vehiculelor automate (Bec et al., 2020). Construcția de autovehicule automate se va dezvolta mult mai consitent şi cu o viteză mai mare prin colaborare între sectoarele şi disciplinele de robotică şi cele care sunt cunoscute pe plan mondial cu sintagma ,automotive industry”. Robotica şi sistemele care funcționează autonom pot să fie implementate în sfera autovehiculelor, astfel încât să contribuie la o anumită îmbunătățire a condițiilor de transport şi trafic (Berns et al., 2021). Multiple sectoare ale activităților industriale beneficiază de aportul roboților încă din a doua parte a secolului XX. Funcționarea acestora a fost îmbunătățită continuu şi funcțiile lor operative au fost dezvoltate pe parcursul timpului (Covaciu et al., 2020). Contribuțiile cele mai recente ale cercetării protocoalelor ingineriei aplicate pentru implementarea instrumentelor de inteligență artificială în domeniul roboților, prin regulatoare fuzzy şi cu ajutorul rețelelor neuronale au permis dezvoltarea unor modele de autovehicule automate în mediul de realitate virtuală care ulterior sunt implementate în practică (Covaciu \& Băldean 2019). În prealabil, roboții sau vehiculele autonome au fost utilizate în sarcini de explorare şi aplicaţii caracterizate de riscuri mari pentru ființele umane (Covaciu \& Băldean 2018). În vederea potențării şanselor de succes, pe durata fazelor de proiectare şi realizare a unor vehicule automate, dotate cu un anumit nivel de inteligență artificială, se parcurg mai întâi etapele calculelor de predimensionare şi verificare. Aplicaţiile robotice se transpun în aplicații de simulare şi apoi în realitatea virtuală pentru a le testa în mai multe condiții de lucru. Vehiculele inteligente au fost şi sunt încă definite ca aplicații ale roboticii (Duchon et al., 2012). În vederea dezvoltării roboților şi 
a sistemelor automate, specialiştii realizează sinteza datelor stadiului actual în baza căreia dezvoltă noi modele structurale şi adaptează funcțiile operatorii la noile cerinţe. Vehiculele robotizate sau automate sunt cunoscute şi ca autovehicule autonome; sunt sisteme care au capacitatea de a sesiza elementele mediului înconjurător şi de a se deplasa fără date de intrare furnizate de un subiect uman sau cu un set minimal de date introduse de om. Vehiculele autonome sau automate sunt echipate cu mai mulți senzori care prelevă date legate de mediul înconjurător (drum, acostament, parapet, poduri, etc.), folosind în acest sens echipament radar, lidar, sonar, GPS, odometru şi senzor inerţial. Unitatea electronică de control şi comandă primeşte şi procesează datele colectate de senzori pentru identificarea căilor de acces disponibile, respectiv pentru identificarea obstacolelor şi a mijloacelor de semnalizare rutieră. Prin analiză şi dezvoltare structurală se pot genera modele de diferite mărimi. Acestea pot fi aplicabile în mai multe condiții de lucru sau exploatare. Anumite considerații privitoare la generarea de suprafețe complexe, în timpul procesului de cercetare şi dezvoltare, permit descoperirea soluției optime pentru aplicația propusă (Hodor et al., 2013). Proiectarea vehiculelor robotizate, destinate transportului de persoane în regim de taxi (aplicaţie deja testată şi funcțională în anumite zone bine definite), pentru transportul de mărfuri şi pentru transportul de pacienți, trebuie să țină cont de funcționarea şi adaptarea sitemului de management al întregului autovehicul automat la diversele sarcini şi solicitări la care va fi supus în exploatare. Pe lângă partea de interacțiune şi comunicare către subiecții umani cu ajutorul echipamentelor on-board, prin intermediul cărora autovehiculul transpune la nivelul habiaclului date esențiale (Jovrea \& Borzan, 2018), mai există şi sistemul de management al grupului motopropulsor (Moldovan \& Borzan, 2017). Unitatea de control habitaclu, unitatea de control motor, unitatea de control a transmisiei, agregatul electro-hidraulic al ABS/ESP (Antilock Braking System/Electronic Stability Program) trebuie să fie optimizate şi adaptate lucrului împreună, astfel încât să ofere atât performanţă cât şi siguranţă în timpul exploatării. Folosind datele furnizate de senzorii sistemelor de parcare se pot programa o serie de funcții ale autovehiculelor robotizate astfel încât acestea să poată fi manevrate în situații dintre cele mai complexe (Schaub et al., 2014).

Procesul de programare a unei ambulanțe robotizate cu aplicații sau instrumente de realitate virtuală nu este total diferit de cel utilizat în cazul unui robot convențional. Pentru orice tip de propulsie utilizată în cazul vehiculelor robotizate, produsul sau prototipul final va fi programat ca un robot standard, dacă funcționarea lui se bazează în principal pe controlul digital. 
Există aşadar două metode sau soluții disponibile pentru utilizarea şi aplicarea inteligenței artificiale (AI) în construcția şi funcționarea unei ambulanțe robotizate. Se poate aplica în acest sens fie logică fuzzy, fie rețele neuronale. Unele dintre aceste aplicații sau sisteme automate şi instrumentele de programare folosite sunt utilizate cu regulatoare sau tehnici fuzzy de control. Sunt impuse o serie de actualizări şi anumiţi paşi de optimizare a componentelor software şi hardware aplicate în domeniul autovehiculelor automate. În zonele metropolitane, pentru inspecția rutieră automată, controlul sunetului şi evaluarea poluării, sunt necesare sisteme robotice. Acestea sunt vitale pentru îndeplinirea sarcinilor complexe de control.

Obiectivul lucrării este de a prezenta modul cum se poate realiza programarea digitală în cadrul procesului de dezvoltare şi proiectare a unui autovehicul automat în cadrul mediului de realitate virtuală atunci când se modelează o ambulanţă robotică operaţională cu Unity 5.6.4. Obiectivele specifice constau în mai multe etape precum sunt următoarele: definirea programelor software şi a materialelor de cercetare specifice. Alte astfel de obiective sunt cele descrise după cum urmează: programarea în software-ul Unity 5, utilizarea unui regulator fuzzy pentru controlul maşinii, proiectarea realizată în aplicaţia de realitate virtuală (virtual reality-VR), configurarea arhitecturii mediului digital, dezvoltarea pistei de testare, crearea altor obiecte virtuale şi protocolul de testare operațională, folosind inteligența artificială, pentru ambulanţa robotică automată dezvoltată în mediul de realitate virtuală (VR), în conformitate cu procedura de transformare şi transfer a datelor prezentată în figura (1.). Cercetarea aplicativă a ideilor literaturii de specialitate şi efectuarea lucrărilor practice de construcție şi dezvoltare a modelului virtual în laborator folosind instrumentele de realitate virtuală conduc apoi la posibilitatea dezvoltării unei ambulanțe robotizate cu tehnică fuzzy. In figura (1.) sunt definite procedurile tehnicii fuzzy şi se indică în patru paşi de bază toate legăturile esenţiale pe linie de comunicare şi de interacțiune ale unui vehicul robotic în raport cu mediul înconjurător.

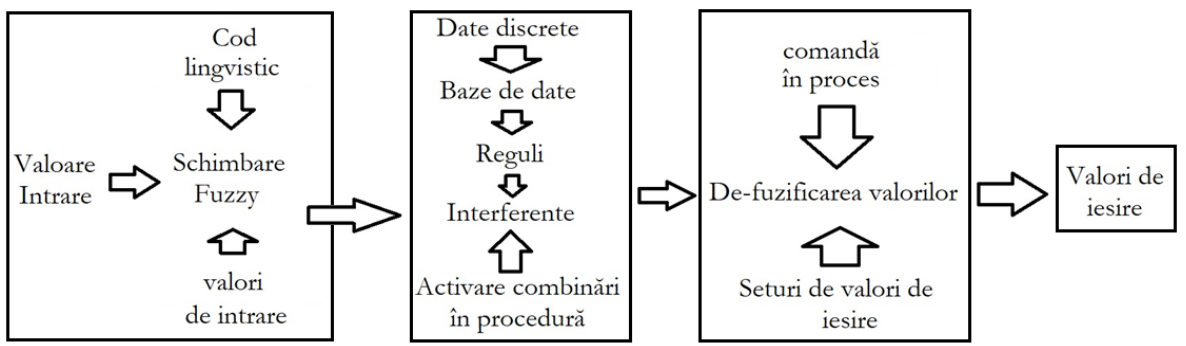

Figura (1.) Procedură de transformare şi transfer a datelor în logică şi control fuzzy 


\section{Materiale şi metodologie}

Sistemul de propulsie este unul dintre cele mai importante sisteme ale unui autovehicul robotizat. Performanţa acestuia trebuie fie determinată prin calcul fie măsurată experimental pentru a fi luată în considerare atunci când se demarează etapele principale din procesul de programare a vehiculului robotizat, datorită variației ample a parametrilor cinematici şi dinamici ce intervin în funcţionare. Dinamica şi cinematica motorului au o influenţă semnificativă asupra propulsiei per ansamblu a vehiculului. La cele mai multe dintre autoturismele obişnuite sau convenționale, conduse de subiecți umani, reglarea fină a parametrilor se face de către şofer în timpul exploatării vehiculului. La autovehiculele robotizate parametrii care sunt vitali pentru exploatare trebuie să fie cât mai complet definiți şi programați. Printre materialele de bază care au fost folosite în cadrul acestei lucrări de analiză şi cercetare aplicativă se regăsesc o serie întreagă de traductori/senzori, actuatori (sau elemente de execuție) şi unităţi electronice de procesare. Traductorii, ca elemente sensibile de analiză a mărimilor mecanice din mediu, îşi au locul în cadrul sistemului pentru că ajută la colectarea unor informaţii din zona înconjurătoare a vehiculului robotic. Aceşti senzori transformă aproape în fiecare caz particular o serie de mărimi mecanice în anumite semnale de natură electrică. Spre exemplu, determinarea valorii efective prin măsurarea unei presiunii într-o roată sau într-un sistem particular, a masei unei substanțe, a gabaritului unui obstacol, a lungimii până la un reper, a vitezei de deplasare, a accelerației unui mobil, a forței şi a puterii generate, reprezintă doar o parte din capacitatea de conversie electro-mecanică pe care o au senzorii sau traductorii. Toate valorile mărimilor mecanice incidente trebuie să fie la un moment dat convertite în valori şi semnale electrice, care la rândul lor vor fi ulterior tranduse într-o serie de mărimi adaptate mediului digital.

Articolul de analiză realizat şi prezentat aici se bazează într-o proporție destul de însemnată pe științele aplicate, folosind pe lângă partea descriptivă şi metode exacte. Acestea din urmă se orientează spre utilizarea şi aplicarea conceptelor specifice roboticii şi eventual chiar a unor materiale din domeniul autovehiculelor speciale utilizate de către echipajele medicale de urgență în vederea testării ipotezelor înaintate şi a protocoalelor propuse spre analiză şi validare. Astfel, în cazul concret al lucrării de faţă, echipa de post-procesare, analiză şi cercetare a datelor aplicative a utilizat informații obținute de către colegul inginer Tudor Andrei Oniga. In principal, cu această ocazie, s-a operat întreg programul de realizare a unui autovehicul special care să poată să se deplaseze automat într-un mediu de realitate 
virtuală. Aceasta din urmă a beneficiat de suport pe calculator cu placă grafică de ultimă generație. Partea esențială de digitalizare, programare şi apoi testarea virtuală s-a realizat în aplicaţia VR, cunoscută drept Unity 5. S-a folosit acest program pentru testarea unui scenariu de deplasare a autovehiculului robotic-automat pe un sector de pistă predefinită pentru astfel de încercări, într-un mediu (environment) specific. Dacă analizăm toate aceste aspecte şi condiții, atunci putem observa similitudinile dintre aplicaţiile de realitate virtuală şi cele de gaming (recreere). Astfel de condiții sunt aplicabile situațiilor specifice din cadrul programelor unui adevărat playstation. Demiurgul în acest caz este programatorul, deoarece el crează atât obiectele dispuse în mediul virtual cât şi întreg spaţiul sau universul realităţii virtuale în care urmează ca acțiunea să se desfăşoare. Pe mai multe planuri apar o serie de aspecte problematice în ceea ce priveşte controlul şi adaptarea performanțelor cinematice şi dinamice la condițiile concrete de deplasare. Lângă autovehiculul robotizat pot să apară subit o serie de factori perturbatori, participanți la trafic sau elemente mobile. În universul sau mediul virtual acestea pot fi destul de uşor considerate drept cantităţi neglijabile sau pot fi controlate prin eliminare efectivă, dar prezența lor fizică este o provocare mai mare şi suficient de reală atunci când se doreşte realizarea de încercări practice şi demararea producției efective.

Metodologia adecvată în cercetarea şi dezvoltarea unei ambulanțe robotizate este simularea, urmată mai apoi de încercarea experimentală şi optimizarea în funcție de condițiile efective. Cercetarea aplicativă este la rândul ei divizată pe de o parte în analiză prin simulare sau modelare virtuală pe unităţi de calcul, prin intermediul cărora se folosesec o serie de scenarii şi modele bazate pe ipoteze simplificatorii, iar pe de altă parte, în validare/invalidare bazată pe încercare experimentală prin deplasare pe traseu, pe pistă de circuit sau pe drumuri reale în vederea colectării valorilor reale. Astfel, în cazul de faţă s-a avut şi se are în vedere pentru etapa de validare a modelelor simplificate din realitatea virtuală şi testarea în condiţii reale. Anumite modele virtuale şi o parte dintre scenariile definite în prima parte a cercetării (aplicate în studiul din realitatea virtuală-R.V.) nu îşi găsesc locul în etapa încercării experimentale.

Figura (2.) reprezintă mediul din Realitatea Virtuală (R.V, virtual reality-V.R.) cu o vedere axonometrică a circuitului din programul Unity 5. 


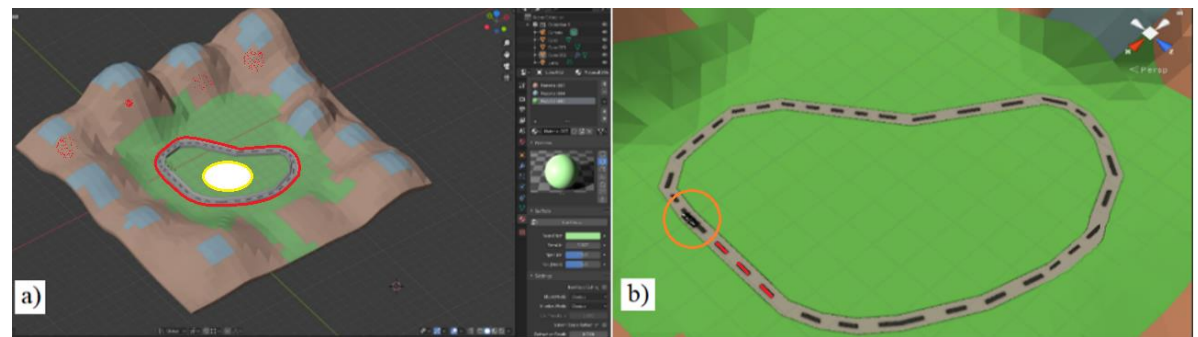

Figura (2.) Vederea axonometrică în Unity 5 a mediului de testare (a) şi a pistei (b)

\section{Rezultate}

În urma analizei posibilităţilor de proiectare şi realizare a ambulanței robotice, a fost conceput un astfel de model ca parte integrantă a scenariului de simulare şi testare într-un mediu special de realitate virtuală implementat în Unity 5. Acesta din urmă este instrumentul digital adecvat pentru cercetarea aplicativă a scenariilor din realitatea virtuală, cu vehicule robotice în condiții cinematice şi reguli de bază predefinite în cadrul unor proceduri de lucru foarte clare. Ambulanța robotică automată este programată să se deplaseze în siguranţă pe traseul specificat dintre două unităti medicale, transportând pacienți Covid pe un drum prevăzut cu o serie de obstacole.

Rezultatele obținute în urma studiului şi analizei virtuale sunt acelea pe care cercetătorul le poate ulterior implementa vehiculelor robotice şi mediului de testare în laborator. Rezultatele practice cuprind atât contribuția ştiinţelor exacte şi a procedurilor standard, care vor fi incluse în vehiculul robotic final. Pe de altă parte însă, atât modelul virtual cât şi produsul final au parte de influența caracterului personal dată de creația individuală care este reprezentată în faţa utilizatorului prin aspectele de formă şi spectru cromatic aplicat. Designul întregului ansamblu al vehiculului robotic, numărul şi tipul de culori, precum şi aspectul suprafețelor sunt factori care contribuie mai mult sau mai puțin direct la calitatea şi succesul produsului final. Utilizatorul sau beneficiarul final nu este ghidat întotdeauna în aprecierea proprie şi în alegerile făcute de către modul de aplicare a procedurilor standard din domeniul ştiinţelor exacte, ci în multe cazuri va fi atras de aspecte superficiale. Combinaţia ingenioasă a aspectelor de design industrial, robotică şi autovehicule rutiere realizează în produsul final acele proporţii care contribuie la succesul mai mare sau mai mic în sectorul de marketing. Armonia suprafețelor, modul de trasare a curbelor şi aspectele de detaliu cromatic, în mod similar cu alte creații ale oamenilor, fac produsul mai mult sau mai puțin vandabil. Aplicând recomandările specialiştilor de marketing, prin metode actuale de proiectare şi dezvoltare, cu programele software moderne, încorporând soluțiile pentru unele nevoi generale, 
dezvoltatorul şi utilizatorul de modele digitale defineşte mediul virtual întrun mod specific, după cum el însuşi şi-l imaginează că vrea să fie.

Unity 5 este un program digital, folosit pe scară largă în procesul de cercetare prin simulare, dezvoltare şi proiectare, care permite creatorului şi utilizatorului de conținut virtual să combine mai multe idei, să asambleze şi să lucreze cu o serie de elemente sau chiar structuri virtuale complexe. Procesele de modelare sunt desfăşurate în acord cu regulile inițiale specificate. În principal, programul menționat poate fi utilizat ca instrument software adaptat operațiilor de simulare, testare digitală şi optimizare a vehiculelor robotice cu funcții de ambulanță în mediul de realitate virtuală. Figura (3.) reprezintă două tipuri de vederi cu autovehiculul robotic destinat pentru serviciul de ambulanţă din cadrul programului Unity 5, precum şi direcția de deplasare pe circuitul virtual. Autovehiculul robotic automat este dotat cu tehnică fuzzy ce ține locul inteligenței artificiale şi care reprezintă suportul logic în fazele de antrenament.

a)

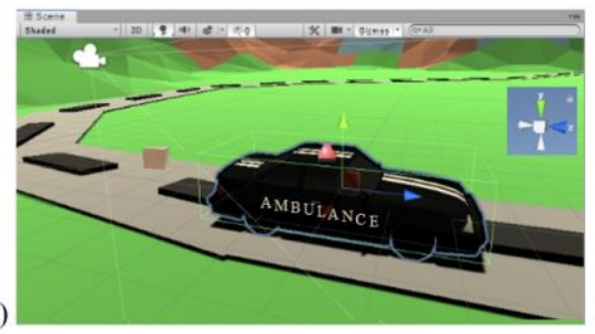

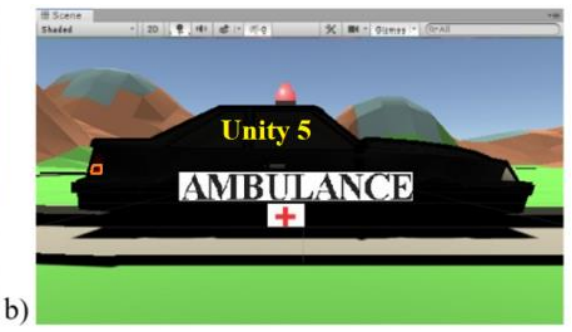

Figura (3.) Vederea axonometrică a ambulanței (a) şi vederea laterală in Unity 5 (b)

\section{Concluzii}

Lucrarea de față a fost elaborată ca un articol ştiințific interdisciplinar. Un astfel de efort crează condiţiile adecvate pentru colaborarea şi descoperirea acelor soluții practice prin care să fie rezolvate probleme dificile din cadrul mai multor domenii care îşi aduc aportul la dezvoltarea şi evoluția socială. Transporturile şi traficul rutier au contribuit şi influențează benefic evoluția societății în ansamblu, dar încă mai există multiple probleme care trebuie depăşite şi soluționate. Multiple variante sau modele ale unor vehicule automate au fost imaginate, proiectate şi apoi testate în diferite condiții aşa cum am arătat şi menționat încă de începutul lucrării. Pentru aplicarea rezultatelor obţinute în scenarii de viaţă cotidiană sau în condiţii reale, cu participanți la trafic şi autovehicule reale trebuie testat mai mult principiul incertitudinii în raport cu modelul dezvoltat. Până în prezent s-au folosit idei convenționale şi autovehicule deja validate în 
practică, atât pentru testarea unor programe de asistență la conducere cât şi pentru dezvoltarea noilor modele de roboți şi rețele vehiculare. Stadiul actual al cercetărilor şi dezvoltării este adecvat pentru pentru colectarea de noi date şi informații care să contribuie la îmbunătățirea şi optimizarea continuă a construcției autovehiculului robotic de tip ambulanţă. Actualmente sunt puse în procedură de testare şi validare mai multe autovehicule automate de serie mică sau prototipuri, cu regim de robo-taxi, în diferite state. Modelele la care sunt transferate protecția cât mai completă şi responsabilitatea aproape integrală a vieții pasagerilor. Mai multe echipe de cercetători şi dezvoltatori lucrează actualmente pe plan internațional pentru optimizarea şi îmbunătățirea acestor vehicule robotice. $\mathrm{Cu}$ toate acestea încă baza responsabilă este tot factorul uman.

Pe lângă unitățile digitale de procesare, programele de simulare în realitate virtuală şi autovehiculele construite pentru încercări, dotate cu senzori, traductori şi actuatori, mai sunt impuse multiple scenarii de validare în practică şi antrenamente în cadrul cărora să fie înregistrate erorile survenite ca urmare a unor greşeli. Toate greşelile trebuie să fie astfel făcute încât să poată fi înregistrate, documentate contextualizat şi ulterior analizate din punct de vedere al interacțiunilor complexe. Se impune o analiză în detaliu pentru a optimiza funcțiile vehiculului robotic ambulanță.

Actualmente, robotica, mecatronica şi programele de realitate virtuală aplicate în domeniul autovehiculelor rutiere oferă posibilități ample de dezvoltare a tehnologiei. Se pot astfel implementa atât în mediul virtual cât şi în modelele de laborator şi apoi în practica efectivă aceleaşi principii utilizate în cadrul programelor de robo-taxi şi robo-race inclusiv în realizarea de autovehicule robotice pentru serviciile de ambulanţă. Personalul implicat în ştiințele exacte (inginerii, tehnicienii s.a.) cât şi cei preocupați de ştiințele umaniste (artişti, designeri, filosofi, psihologi) au azi oportunitatea să contribuie în procesul dezvoltării modelelor virtuale şi chiar să testeze propriile idei pe diferite paliere. Propunerea iniţială este pentru iniţierea unui demers de cercetare în spațiul de realitate virtuală. În cele din urmă fiecare dintre noi poate fi dezvoltatorul unui model personalizat pe care îl poate valida cu instrumente digitale şi apoi îl poate promova.

\section{References}

Andrei, L., Băldean, D.L., \& Borzan, A.I. (2020). Designing an Artificial Intelligence Control Program Model to be Tested and Implemented in Virtual Reality for Automated Chevrolet Camaro. Multidisciplinary Digital Publishing Institute Proceedings, 63(1), 44. https://doi.org/10.3390/proceedings2020063044 
Bec, P., Borzan, A.I., Frunză, M., Băldean, D.L., \& Berindei, I. (2020). Study of Vulnerabilities in Designing and Using Automated Vehicles based on SWOT method for Chevrolet Camaro. IOP Conference Series: Materials Science and Engineering, 898(1).https://doi.org/10.1088/1757-899X/898/1/012008

Berns, K., Gini, M., \& Ota, J. (2021). Robotics and Autonomous Systems. ScienceDirect, 142(1).

Covaciu, F. A., \& Băldean, D. L. (2018). Designing and Control of a Exploration Mobile Robot, Using Virtual Reality as a Simulation Environment. In A.I. Chereches, \& M. Bejan (Eds.), Stiință şi inginerie. AGIR.

Covaciu, F. A., \& Băldean, D. L. (2019). Contribution to Research of the Applied Engineering Protocol to Implement a Fuzzy Regulator for Autonomous Driving of an Automotive Model Implemented in Virtual Reality. In I. Dumitru, \& D. Covaciu (Eds.), The 30th SLAR International Congress of Automotive and Transport Engineering Science and Management of Automotive and Transp. Engineering (pp. 468-476). Springer International Publishing.

Covaciu, F. A., Bec, P., \& Băldean, D. L. (2020). Developing and Researching a Robotic Arm for Public Service and Industry to Highlight and Mitigate Its Inherent Technical Vulnerabilities, Multidisciplinary Digital Publishing Institute Proceedings, 63(1), 3025. https://doi.org/10.3390/proceedings63013025

Duchon, F., Hubinsky, P., Hanzel, J., Babinec, A., \& Tolgyessy, M. (2012). Intelligent Vehicles as the Robotic Applications. Procedia Engineering, 48, 105 - 114. https://doi.org/10.1016/j.proeng.2012.09.492

Hodor, A., Berce, P., \& Comes, R. (2013). Some Considerations About 3D Replication of Complex Surfaces. Acta Technica Napocensis, 56(1), 153 - 158. https://atna-mam.utcluj.ro/index.php/Acta/article/view/437

Jovrea, S., \& Borzan, A. I. (2018). Researching On-board Display of Essential Information. In A.I. Chereches, \& M. Bejan (Ed.), Stiintă şi inginerie. AGIR.

Moldovan, A., \& Borzan, A. I. (2017). Experimental Research of the Management System from the Peugeot 4007 S.U.V. In A.I. Chereches, \& M. Bejan (Ed.), Stiintă ş si inginerie. AGIR.

Schaub, A., Cruz, J.C.R., \& Burschka, D. (2014). Autonomous Parking using a Highly Maneuverable Robotic Vehicle. IF AC Proceedings Volumes, 47(3), 2640-2645. https://mediatum.ub.tum.de/doc/1281587/file.pdf 